\title{
TRAFFIC MANAGEMENT SYSTEM IN TERMS OF DATA EXCHANGE
}

\author{
DUŠAN KAMENICKÝ
}

\begin{abstract}
Czech Technical University in Prague, Faculty of Transportation Sciences, Department of Transport Telematics, Konviktská 20, Prague, Czech Republic
\end{abstract}

correspondence: kamendus@fd.cvut.cz

\begin{abstract}
Prediction of train running and IT support of conflict resolution decision for an efficient use of the existing railway infrastructure is needed. To meet these requirements standardized interfaces between infrastructure managers and railway undertakings and infrastructure description are indispensable.
\end{abstract}

KEYWORDS: technical specification for interoperability, infrastructure description, traffic planning, dispatching, train controlling, telematics applications, railML, RailTopoModel.

\section{INTRODUCTION}

With the increasing demand for freight and passenger transport railway subjects aims on increasing the capacity by a reduction of delays and improved traffic fluidity. To meet these requirements modern traffic management systems are implemented. They are based on a prediction of train running and automatic conflict resolution. Standardized interfaces shall ensure the needs of the railway undertakings, infrastructure managements and customers of different European countries in traffic planning, dispatching and train control.

Directive 2008/57/EC of the European Parliament and of the Council of 17 June 2008 on the interoperability of the rail system within the Community defines in Annex II infrastructure, energy, control-command and signaling and rolling stock as structural subsystems of the rail system, and traffic operation and management, telematics applications for passenger and freight services as a functional subsystem of the rail system. Specifications are drafted by the European Railway Agency and adopted in a Decision by the European Commission, to ensure the interoperability of trans-European rail system.

The paper describes data exchange with focus on the operational management.

\section{Architecture of Management PROCESS}

Railway management process can be divided into three basic layers: traffic planning, dispatching and train controlling.

Traffic planning can be characterized as conceptual planning, strategic network development, service planning and infrastructure planning in long term, timetabling in short term. Timetabling is a process concerning transport demand by customer and path requests and allocation by railway undertakings and infrastructure managers [1. Traffic planning is influenced by transport demands, infrastructure parameters, rolling stocks parameters and path fees. Traffic planning shall define rules, like priorities of the train and competence between railway undertakings and infrastructure managers.

The aim of dispatching is at close approximation to scheduled state, from which railway system has been deflected by external influences. IT support is necessary in dispatcher decision processes [2]. Quality and timeliness of information is necessary condition the dispatcher could correctly decide the intervention, which leads to fulfillment of the planned timetable.

Infrastructure manager dispatcher is responsible for changing train sequences to minimalize deviations from the timetable. Railway undertaking dispatcher is responsible for skipping a commercial stop, breaking a connection, providing rolling stock and staff.

Major incidents forcing those decisions like rolling stock or infrastructural failures with a following adaptation of the timetable require a close communication between infrastructure manager and railway undertaking.

Train controlling is process train route setting, shunting route managing and setting, infrastructure elements controlling to ensure railway safety. Routine processes can be performed by automatic train route setting system.

Automatic train control system, which is designed to eliminate human error, can be supplemented by automatic train operation system or driver advisory system. A train movement is adjusted to achieve defined points of infrastructure in defined time slot and therefore to reduce energy consumption and increase the capacity at a time.

\section{STANDARDIZED INTERFACES}

Technical parameters of infrastructure elements, like line layout, track parameters, switches and crossings, 
platforms etc. are defined by 1299/2014/EU "Technical specifications for relating to the infrastructure subsystem of the rail system in the European Union" 3 . With exception of the requirements for infrastructure register, infrastructure description, methodology of representation or the storage of infrastructure data are not defined.

Infrastructure register is defined by $2014 / 880 / \mathrm{EU}$ "Specifications of the register of railway infrastructure" [4]. This specification concerns data about the infrastructure structural subsystem the energy structural subsystem, and the trackside control-command and signaling subsystem.

Railway network shall be subdivided into sections of line and operation points. Section of line means the part of line between adjacent operational points and may consist of several tracks. Operational point means any location for train service operations, where train services may begin and end or change route and where passenger or freight services may be provided [5].

The structural subsystems specific requirements that interoperable railway lines and rolling stock must meet and many of these requirements must be stored in the infrastructure registers and the register of rolling stock. Comparing those registers should make it clear which lines accept which rail vehicles.

Telematics applications for passenger and freight services subsystem equipment are defined by $2006 / 62 / \mathrm{ES}$ "Technical specification for interoperability relating to the telematics applications for freight subsystem of the trans-European conventional rail system" (TSI TAF) 6] and 2011/454/ES "Technical specification for interoperability relating to the subsystem telematics applications for passenger services of the transEuropean rail system" (TSI TAP) [7].

The specifications relating to telematics applications define architecture of information system and interfaces among subjects: infrastructure manager, railway undertaking and customer. Processes and data exchanges to allocating of train path and monitoring train movement are defined. Fundamental processes are:

- Train path request - path departure point, path departure time, path destination point, command and control system including on-board radio equipment, train weight and length, braking system and braking performance, maximum speed, RID numbers relating to any dangerous goods, information concerning exceptional gauging etc.,

- Train composition message - for the preparation of the train, railway undertaking must have access to the infrastructure restriction notice, to technical wagon data (rolling stock reference database), to the dangerous goods reference file and to current updated information status on the wagons (the wagon and intermodal unit operation database),

- Train ready - message must be sent to indicating, that train is ready for departure,
- Train running information and train running forecast.

Interface between telematics applications and subsystem "Control-command and signaling" is not specified, although interlocking equipment need data on the parameters of the trains. Interface between telematics applications and subsystem "Infrastructure" is given with the train path data definition and via the infrastructure restriction notice database. Interface between telematics applications and subsystem "Rolling stocks" is only given via the rolling stock reference database.

The procedures enabling a coherent operation of various structural subsystems during both normal and degraded operation are defined by $2015 / 995 / \mathrm{EU}$ "Technical specification for interoperability relating to the operational and traffic management subsystem of the rail system in the European Union" [8].

From the viewpoint of the data exchange, relevant is requirement of Route Book and Timetables. The development of the Route Book is the responsibility of $\mathrm{RU}$ and should be prepared in the language of the railway undertaking. However, the format of the Route Book is not specified.

Each train must be identified by a train running number. The train running number is given by the infrastructure manager when allocating a train path. The train running number format is defined in Commission Decision 2012/88/EU.

Interfaces among different railway IT applications weren't specified. The railML.org initiative was founded in 2002 in order to create an interface to enable heterogeneous railway applications to communicate with each other [9]. The result has been the development of the Railway Markup Language - railMLwhich delivers a universally applicable data exchange format. The railML standard has been developed by infrastructure managers, railway undertakings, software and consulting firms and academic institutions from number of countries.

The railML specification contains subschemas for four main areas: infrastructure, timetable, rolling stock and interlocking. RailML can be seen as a direct use case of the RailTopoModel.

The RailTopoModel is a logical object model to standardize the representation of railway infrastructurerelated data [10]. On the other side, RailTopoModel will become International Railway Standard (IRS) in spring 2016, compiled by UIC, the largest railway organization worldwide.

SNCF Réseau has worked since 2011 to develop its global model for railways business objects, Ariane Model, based on the same principles as RailTopoModel. Ariane Model now covers the description of all functional objects and properties of the network, at track and lines levels, including topology, referencing and topography, routes description and signaling. On 2016-2017 catenary and power supply network, and finalization of rolling stock will be added. 


\section{Coclusion}

Technical specification for interoperability defines technical requirements of infrastructure, energy and rolling stocks parameters and control-command and signaling system to enable interoperable vehicle driving on interoperable infrastructure. Necessary data exchange relating to path allocation and operation and management processes relating to ensure safety are defined in function subsystems. However, data exchange relating to dispatching is not standardized. Infrastructure description, specified in infrastructure register, is not sufficient for prediction of train running. Data exchange relating to train parameters, like traction characteristics, and timetable requirements is not specified. Infrastructure managers and railway undertakings interface ensuring dynamic data exchange relating to breaking a connection is not defined in technical specification for interoperability.

RailML seems to become effective tool for data exchange supporting prediction of train running and conflict resolution decision among others.

\section{REFERENCES}

[1] Birgit Jaekel, Thomas Albrecht. Operational railway management as part of an integrated railway management process, 2014. EURO - ŽEL, Žilina.

[2] D. Kamenický. Optimalizační algoritmy pro systémy řízení a zabezpečení železniční dopravy, Studie k disertační práci, 2015. ČVUT v Praze, Fakulta dopravní, Praha.

[3] 1299/2014/EU "Technical specifications for relating to the infrastructure subsystem of the rail system in the European Union".

[4] 2014/880/EU "Specifications of the register of railway infrastructure".

[5] J. Barnet. Rail Infrastructure Informational Description, Master Thesis, 2011. CTU in Prague, Faculty of Transportation Sciences, Prague.

[6] 2006/62/ES "Technical specification for interoperability relating to the telematics applications for freight subsystem of the trans-European conventional rail system".

[7] 2011/454/ES "Technical specification for interoperability relating to the subsystem telematics applications for passenger services of the trans-European rail system".

[8] 2015/995/EU "Technical specification for interoperability relating to the operational and traffic management subsystem of the rail system in the European Union".

[9] RailML website [online]. [2016-01-25], http://www.railml.org/en/

[10] RailTopoModel website [online]. [2016-01-25], http://www.railtopomodel.org/en// 